\title{
The Influence of Classroom Learning Environment toward Students' Vocabulary Acquisition: A Study on Second Semester Junior High School Students
}

\author{
Ahmad Baihaqi; Sudirman Wilian; Nuriadi \\ English Graduate Department, University of Mataram, Indonesia
}

http://dx.doi.org/10.18415/ijmmu.v6i2.762

\begin{abstract}
The aim of this study was to determine whether or not classroom learning environment strategy is effective to increase students' vocabulary acquisition. The research design was experimental study. There were four groups in this design; two groups for experimental group and two groups for control group. The sampling technique was random sampling which meant each subject or unit has an equal chance of being selected. The technique of data collecting in this research were documentation and testing. Data was analyzed by using t-test formula and t-table. The sample for this study consisted of one hundred and sixtyfour (164) students. The data were collected through pre-test, treatment, and post-test where the experimental groups were treated by classroom learning environment strategy whereas the control groups were treated by using common teaching. The finding showed that the t-test value was higher than t-table. 5.3839 and $7.0249>1.990$ at significant level .055 .3839 and $7.0249>2.6386$ and 2.6371 at significant level .01 in degree of freedom (df) 80. It showed that classroom learning environment strategy gave significant effect on students' vocabulary acquisition at grade VII of SMPN 7 Mataram in academic year $2018 / 2019$.
\end{abstract}

Keywords: Classroom Learning Environment Strategy; Experimental Study; Vocabulary Acquisition

\section{Introduction}

Vocabulary teaching is one of the most important components of any language class. The main reason is the fact that it is a medium, which carries meaning; learning to understand and express the meaning. Vocabulary is also a cornerstone in language learning, without which any language could not exist. Therefore, learning vocabulary in order to be able to communicate in one language, students should have as many words as possible.

One of the most important and inflectional factors that may affect vocabulary learning and acquisition in class is the classroom setting and environment. In many schools, in Indonesia the environment and the classroom setting do not help to facilitate the vocabulary learning. Many schools for example, do not provide picture, chart, or many contents aid for the students to learn. Many schools in Indonesia only have desks, chairs, blackboard or white boards, cupboard, chalk or board marker, and picture of the president and vice president of the Republic of Indonesia hanging on the wall. Such as in the city of Mataram mostly schools do not provide classroom set by learning environment in teaching 
English. One of the schools in the area does not provide the suitable classroom for teaching is at SMPN 7 Mataram. This is in line with what Hill (1990) pointed out that "the standard classroom" in many schools is usually not a very suitable environment for learning languages.

Theoretically, in order that students can get as many inputs as they can, they should be provided with media such as pictures, chart of list of words, and other teaching aids like realia, sound system media. English lesson in every school in Indonesia starting from junior high school until senior high school is a compulsory subject and is tested in the national final exam. The importance of this lesson to be taught properly should be the main concern for every English teacher. Good teaching and making the learners easier to understand the foreign language starting by the exposure of pictures in class could be a starting point of teacher's effort. One of the most important components that makes the skills easier to learn. Generally, EFL learners face to learn especially retaining in words, and they complaining about forgetting the words soon. Therefore, one of the solutions to this problem is by telling the learners using the picture in the classroom.

Therefore, this research is very important to do in order to make learners the use of pictures is very useful in the teaching and the learning process because it makes the classroom dynamic and lively, so the pupils can be highly motivated and have a lot fun during the lesson, besides that the teacher should establish conditions which make teaching vocabulary possible.

Additionally, the success of communication is dependent on the accurate vocabulary understanding. Schmitt (2000, p.19) states that one of the key elements in learning foreign language is mastering the L2' vocabulary. This meets Wilkins's (1972, p.111) point of view which stated that without grammar very little can be conveyed, without vocabulary nothing can be conveyed. Teaching vocabulary becomes the task of most teachers to help EFL learners enlarged their vocabulary mastery. Therefore, it has an integral importance in EFL classes. Hence, in this chapter, we will cast the light on vocabulary definition, types of vocabulary: productive and receptive, describing the two branches of vocabulary lexicography and lexicology, the importance of vocabulary, techniques and steps in teaching vocabulary. Additionally, word knowledge comes into two kinds: receptive (listening and reading) and productive (speaking and writing).

\section{Concept of Teaching Vocabulary}

Teaching is a process of information or knowledge transfer between teacher and students in the classroom, outdoor or in door, the act of giving information. Good technique is needed in a process of teaching vocabulary in order to help the students get the meaning and use the words. Gnainoska (1998:12) states that teaching vocabulary can be meaningful if the teacher can conduct the teaching process by combining the available technique of teaching by providing a good technique of teaching. It is hoped that will be more enjoyable, interesting, and motivating to the students, they will not be bored in the teaching learning process.

Furthermore, Sutarjo (1998:24) states that there are five possible ways of teaching vocabulary. First, teaching vocabulary through creativity. By using this technique, the teacher allows the students to decide what they want to learn. The teacher can use such a technique to encourage the students to be creative for producing the vocabulary, such as using picture, puzzle, providing keywords, and game. Second, teaching vocabulary through context clues. In this technique, the teacher can use a context clue in surrounding context, for example give the antonym and synonym.The third is teaching vocabulary through translation. This technique is considered as ancient one and here the teacher teaches the meaning of the word through translation. The fourth way is teaching vocabulary through guessing. In this case, the teacher can encourage the students to guess the word first and then consult it. To guess the right word, a student should have a good rationale. The teacher can draw five pictures on the board and then teacher pronounces the word and asks a student to point the picture mean. The last is teaching vocabulary through derivation. This technique requires the teacher to involve the four classes of words on the basis of their position of occurrences in English sentence pattern. The teacher can give noun, verb, adjective and adverb. According to those five possible ways of teaching vocabulary, the researcher applied picture series as a technique in this research. Teaching vocabulary is the vocabulary teaching process in order to 
help the students get the meaning and use the words. It also including meaning, pronunciation and spelling to teach the vocabulary.

\section{Teaching Vocabulary}

Teaching English as a foreign language is not an easy task to deal with, it needs successful teachers whom should be aware of the importance of target language aspect while teaching EFL classroom. Deliberately teaching vocabulary is one of the least efficient ways of developing learners vocabulary knowledge but nonetheless it is an important part of a well-balanced vocabulary programme. Paul Nation (1978a) states that the main problem with vocabulary teaching is that only a few words and a small part of what is required to know a word can be dealt with at any one time. This limitation also applies to incidental learning from listening or reading, but it is much easier to arrange for large amounts of independent listening and reading than it is to arrange for large amounts of teaching. Teaching can effectively deal with only a small amount of information about a word at a time. The more complex the information is, the more likely the learners are to misinterpret it.

Learning any particular word as being a cumulative process where knowledge is built up over a series of varied meetings with the word. At best, teaching can provide only one or two of these meetings. The others involve deliberate study, meeting through meaning-focused input and output, and fluency development activities. The positive effects of vocabulary teaching are that it can provide help when learners feel it is most needed. This is particularly true for vocabulary teaching that occurs in the context of message-focused activities involving listening, speaking, reading and writing, and where the teaching deals with items that learners see as being very relevant for the activity. The small amount of research on such teaching indicates that it has a strong effect on vocabulary learning. The first decision to make when teaching a word is to decide whether the word is worth spending time on or not. If the word is a low frequency word and is not a useful technical word and not one that is particularly useful for the learners, it should be dealt with as quickly as possible. Usually when words come up in the context of a reading or listening text, or of learners need a word or phrase when speaking or writing, they need quick help which does not interrupt the activity too much. Sometimes however a teacher may want to spend time on a word. In general, time should be spent on high frequency words or words that fill a language need that the learners have. When deciding how to spend time on a word, it is useful to consider the learning burden of the word.

\section{Techniques in Teaching Vocabulary}

There are several techniques that can be applied in teaching vocabulary, such as TPR (Total Physical Response), GTM (Grammar Translation Method), or other teaching technique.More importantly, teachers have to vary techniques in presenting and explaining the meanings of new vocabulary items to their learners. Thus, the teacher's intervention is required. The technique by Nation (1978 a) is useful way of learning new vocabulary, in particular becoming familiar with the spoken form of the word and linking it to its meaning. The teacher gradually communicates the meaning of the word by using it in context. When learners think they know what the word means, they raise their hands. After enough hands and raised, the teacher asks a learner for translation or explanation of the meaning. The teacher's description might go like this. The word being taught is precise.

When using this technique several things are important. First, not too much information is given about the word at the beginning, so that the learners have to listen attentively to the word in a range of context. Second, the teacher repeats the sentences saying each sentences. The teacher does not ask the first learners who raise their hands for the meaning of the word (a translation, a synonym, or a definition), but keeps on describing until most of the class have raised their hands. This is another way of saying that there are features in the effective use of the technique that encourage learning. These design features are the repetition of the word and its context, the presence of variety of rich contexts, and the need to give careful attention to the word and its contexts in order to be able to complete the activity by working out its meaning. 
These features set up conditions that research tells us are important for language acquisition. These conditions include having a positive attitude to the activity (helped by its puzzle-like nature), noticing the item several times and thoughtfully processing its meaning. These condition help reach the vocabulary learning goal. It is therefore important that teachers are aware of the important features of techniques so that they know how to use them and what to look for when they are being used (Loschky and Bley-Vroman, 1993: 165).

There are three important general processes that may lead to a word being remembered. These comprise noticing (through formal instruction, negotiation, the need to comprehend or produce, awareness of inefficiencies), retrieval, and creative (generative) use. The first process encouraging learning is noticing, that is giving attention to an item. This means that learners need to notice the word, and be aware of it as a useful language item (see Ellis, 1991; McLaughlin,1990; Schmidt, 1990 for discussions of noticing). This noticing may be affected by several factors, including the salience of the word in the textual input or in the discussion of the text, previous contact that the learners have had with the word, and learners' realization that the word fills a gap in their knowledge of the language (Schmidt and Frota, 1986; Ellis, 1990). Noticing also occurs when learners look up a word, guess from context, or have a word explained to them.

The second major process that may lead to a word being remembered is retrieval (Baddley, 1990: 156). A word may be noticed and its meaning comprehended in the textual input to the task, through teacher explanation or dictionary use. If that word is subsequently retrieved during the task, then the memory of that word will be strengthened. Retrieval may be receptive or productive. Receptive retrieval involves perceiving the form and having to retrieve its meaning when the word is met in listening or reading. Productive retrieval involves wishing to communicate the meaning of the word and having to retrieve its spoken or written form as in speaking or writing. Retrieved does not occur if the form and its meaning are presented simultaneously to the learner.

The third major process that may lead to a word being remembered in generation. There is now an increasing number of studies that show that generative processing is an important factor in first and second language vocabulary learning. Generative processing occurs when previously met words are subsequently met or used in ways that different from the previous meeting with the word forces learners to reconceptualise their knowledge of that word. For example, if a learner has met the word cement used as a verb as in 'we cemented the path' and then meets 'we cemented our relationship with a drink', the learner need to rethink the meaning and uses of cement and this will help firmly establish the memory of this word. Generative use is not restricted to metaphorical extension of word meaning and can apply to a range of variations from inflection through collocation and grammatical context to reference and meaning. Joe (1995) found that quality of knowledge as measured by three different tests of each word in retelling task. R. Ellis (1995) found that a factor he called 'range' was significantly related to vocabulary learning in a negotiated listening task. The task involved second language learners listening to directions and having to place items on a picture. 'range' referred to the number of separate directions that a word occurred in, and could be considered a kind of measure of generativeness.

\section{Steps of Teaching Vocabulary Acquisition in EFL Classes}

According to Nation and Newton cited in (Coady. J, Huckin. 1997 p.239) the decision about what vocabulary will be selected for teaching is very important, as well as how it will be sequenced.

\section{Selecting}

Many researchers fetched for appropriate and useful vocabulary that contributes in successful learning and acquiring it. They provided lists of the most widely used words in early stages of learning (they estimated 2000 words). Furthermore, they add as a second factor of vocabulary selection the range of words used in spoken language. Their interest do not just on frequency and range but also they added other factors such as, combination (the ability to combine with other words), definition (the ability to help define other words), and the substitution which means the ability to replace one word with another. The 
most appropriate learning strategy here is "Selective attention", that is the teacher should draw the learners' attention to the target word and ensures that notes it. The teacher can do this through underlining, bold-facing and circling. (Coady, J. J, Huckin.T. 1997, p.239)

\section{Sequencing}

The second step of teaching vocabulary is sequencing according to Nation (1990) base on him. There are two main sequencing which the teacher should follow: first, is the sequence of levels of vocabulary. Second, is grouping and ordering of words. The ordering means the way in which the word is presented, simply it is concerned with the form and meaning, which one is presented first. The division for the levels for vocabulary is demonstrated in the following table adapted from Nation (1990).

Table 1 levels of acquiring vocabulary as cited in (Coady. J, Huckin. T.p.)

\begin{tabular}{|l|l|l|}
\hline Levels & Number of words & Text Coverage \% \\
\hline High frequency words & 2000 & 87 \\
\hline Academic vocabulary & 800 & 08 \\
\hline Technical vocabulary & 2000 & 03 \\
\hline Low frequency words & 123.200 & 02 \\
\hline Total & 128000 & 100 \\
\hline
\end{tabular}

The process of acquiring English vocabulary contains many levels. First, at the very beginning of studies learners have to acquire 2000 high frequent words which its text coverage is $87 \%$, in order to use them in productive skills. Next, if the learners want to carry on their studies, she/he must learn some academic words that arrived to 800 words and text coverage is $8 \%$. Technical vocabulary is listed around it is used with specific domain; such as: medicine, law, physics and mathematics. Though, low frequency words cover $2 \%$, this percentage transferred to an approximately number 123 words. They are learnt for the use of English for social purposes.

During the lesson, teachers have to be aware about the way of explaining new items. It is better to present unconnected items in meaning and form rather than presenting items that are synonyms or opposites. For example: the learners mixed the forms and meanings of words such as "inside" with the word "outside" have been taught at the same time. After the lesson, learners cannot be certain if inside means "inside" or "outside". Therefore, it is important for teachers to bear in mind the knowledge of grouping new items. Teaching English vocabulary has another important factor which is ordering of items. Different items should not be taught separately. It means that for the sake of producing meaningful sentences, there must be a kind of combination between these words.

\section{Presenting}

After selecting and sequencing the items to be taught, the next step to be dealt with in presentation, teacher use vocabulary exercise or individual learning in teaching high frequency vocabulary because, it occurs in few numbers. In contrast, low frequency words are numerous in number. As Kelly (1990) has pointed out, guessing is not a substitute for systematic learning of lexis (adapted by Hatch. E, Brown. C, 1995, p.240).

Both of teachers and learners are concerned with development strategies, here the teacher role is to provide the effective development strategies which help to enhance learners' learning. There are different principles for dealing with high and low frequency vocabulary. They can be put into practice directly or indirectly, the realization of these approaches call for the reflexing and planning from the 
teacher. In a direct approach of teaching includes word building for instance crossword puzzles activities, or using pictures in activities, it means that instructors have to use explicit activities. While, in an indirect approach to vocabulary teaching, the activities should be implicit, consequently vocabulary learning depends on communicative activities such as: listening stories.

Mastering vocabulary is very important to learn English as second or foreign language. Therefore, it is necessary to teach vocabulary to learners in order to provide them with sufficient number of words. Further, it enables them to acquire the target language that lead to effective communication. However, the process of teaching vocabulary is difficult to deal with, thus it needs a successful teacher to achieve the learners' needs about enlarging their word knowledge. Additionally, teachers have to search for techniques that may build an appropriate atmosphere and motivate pupils to learn better. More precisely, they familiarize learners with new vocabulary and help them consolidate lexical knowledge of words.

There is a known English idiom that says" a picture is worth a thousand words". Pictures have a major role to play in language classroom. They are an effective resource for the teaching /learning process and contribute in the progression of language skills. Moreover, pictures are precisely used in teaching young learners since they are not yet able to understand words and long phrases, the utilization of a didactic aid is required in this process. Showing pictures to what's being taught is a good way to build student' engagement. It is also enriching learners' memories in which they can store vocabulary. Furthermore, this aid helps to bring outside world into classroom easily besides that; it triggers the learner's imagination and creativity. Additionally, the use of pictures during the lesson delivery can likely sustain the attention, interest of the student and make it enjoyable. Hence, in this chapter, we will cast the light on pictures definition, types of pictures, the criteria of good picture, also the advantages of using pictures in teaching English language, using pictures in teaching vocabulary, ways of using pictures as a teaching strategy and activities where pictures are used to teach vocabulary.

\section{Using Pictures in Teaching Vocabulary}

Teaching new words to EFL classes, particularly to young learners, is not an easy task; teachers have to provide many kinds of techniques in order to facilitate learning and teaching new vocabulary. Pictures are one technique that can be used to show the meaning of the lexical items. They will enable learners to learn, understand and utilize vocabulary in all aspects of their life.

Real objects, pictures, etc. are often seen as the most valid way of communicating the meaning of a word, but as Nation (1978b) points out, all ways of communicating meaning involve the changing of an idea into some observable form, are indirect, are likely to be misinterpreted, and may not convey the exact underlying concept of the word. An advantage of using actions, objects, pictures or diagrams that learners see an instance of the meaning and this is likely to be remembered.

Harmer (2001 p.134 states that" teachers have always used pictures or graphics-whether drawn, taken from books, newspapers and magazines, or photographs- to facilitate learning". As a support, Virginia French (1983 p.24) says that "for helping students to understand the meaning of a word, we often find that a picture is useful". Simply, pictures can be used to explain the meaning of vocabulary items. In addition, Philips (1993 p.74) writes," vocabulary is best learned when the meaning of word (s) is illustrated for example by a picture, an action, or a real object". In other words, pictures can be a best mean for presenting of vocabulary.

Harmer (2001 p.135) states that, "one of the most appropriate uses for pictures is for the presenting and checking of meaning of the word airplane, for example, is to have a picture of one". This means, the picture is very beneficial in showing and reviewing the meaning of certain words. This is supported by Diane and Freeman (2000 p.29)," teacher who use the Direct Method believe students need to associate meanings and the target language directly. In order to do this, when the teacher introduces a new target language word or phrase, he demonstrates its meaning through the use of realia, pictures, or pantomime: he never translates it into the students' native language". In a nutshell, teachers try to use 
pictures in teaching vocabulary in order to make the process entertaining and memorable. Besides that, they deepen their understanding of concepts; therefore, the learner's vocabulary mastery will be increased.

\section{Methodology}

This research was expected to discover the significant influence of classroom learning environment setting through pictures and vocabulary lists toward students' vocabulary acquisition at junior high school. Therefore, this research was going to be approached using experimental method, in which four classes were taken as experiment and control classes or groups. Thus, the present study used two groups as experiments, which received treatment, and two others as control groups, which had no treatment at all. The researcher gave pre-test and post-test to the four classes. Pre-test was intended to measure the students' vocabulary acquisition before the treatment. After the treatment, the researcher gave a post-test to see if there was an improvement on the students' vocabulary acquisition.

This research was conducted in the second semester of the academic year 2019. The Research was conducted based on the semester program from January through March 2019 in grade VII of SMPN 7 Mataram. The population of this study was the whole students of the seventh grader of the school. Out of the eleven classes, comprising approximately 457 students, four classes had chosen randomly as the samples of the study.

Based on the choice of classes as the samples this research could be considered as using cluster sampling technique. A cluster sampling is used to determine sample if the object or the data source is too broad (Sugiyono, 2011). Therefore, class VII A and VII B had chosen as the experiment groups and class VII C and VII D as the control groups. Each class comprises of 40 through 43 students.

In order to collect the data, pre-test was given to the both of the groups. It was followed by giving treatment about four times for each group. The experimental group was treated by using classroomlearning environment through pictures and vocabulary lists and the control group was treated by using common teaching technique. After giving treatment, the post-test was conducted to the both of the groups based on material will be given in treatment.

Analyzing the data of this study involved collecting students' pre-test and post-test, the students' answer base on the result is asses by using the division for the levels for vocabulary is demonstrated in the following table adapted from Nation (1990).

After giving the grades for result of student test, the researcher inserts the students' score into the table data. The researcher further found the mean deviation score of the pre-test and post-test by using the formula below:

The formula for experimental group:

In whi

$$
\begin{aligned}
& \mathrm{Mx}=\sum \mathrm{dx} \\
& \mathrm{N}
\end{aligned}
$$

The fo

„roup:

$$
M y=\sum_{N}^{\sum d x}
$$

Mx : the mean score of experimental group

My : the mean score of control group

$\sum \mathrm{dx} \quad$ : the sum of deviation score of pre-test and post-test of experimental group

$\sum$ dy $\quad$ : the sum of derivation score of pre-test and post-test of control group 
$\mathrm{N}$ : number of sample

The next step was calculating the square deviation by using the following formula:

The square deviation of experimental group:

$\sum \mathrm{x} 2 \sum \mathrm{d} \mathrm{x} 2-\frac{\left(\sum \mathrm{dx}\right) 2}{2}$

The square deviation of control group:

$$
\sum \mathrm{x} 2 \sum \mathrm{dx} 2-\frac{(\Sigma \mathrm{dx}) 2}{2}
$$

Then the researcher calculates the correlation coefficients of the two mean scores whether they were categorized as significant or not, the formula was below :

$$
\mathrm{t}-\text { test }=\frac{m x-m y}{\sqrt{\left(\frac{\sum \mathrm{x} 2+\sum \mathrm{y}^{2}}{N x+N y-2}\right)\left(\frac{1}{N x}+\frac{1}{N y}\right)}}
$$

In which,

t-test : the degree of differences

Mx : the mean score of experiment group

My : the mean score of control group

$\mathrm{Nx}$ : the number of sample of experimental group

$\mathrm{Ny}$ : the number of sample of control group

(Arikunto, 2010)

The result of the test can be interpreted by using the following formula:

1. If $\mathrm{t}$-test $\geq \mathrm{t}$-table at the confidence level 05 and $01, \mathrm{H}_{0}$ is rejected.

2. If $\mathrm{t}$-test $<\mathrm{t}$-table at the confidence level 05 and $01, \mathrm{H}_{0}$ is failed to be rejected.

\section{Results and Discussions}

The result could be interpreted based on the statistical analysis of the data obtained. From the different score of pre-test and post-test of fourth groups namely the experiment and control groups, they are clearly shown that there were significant effect of classroom learning environment through pictures and vocabulary lists at grade VII in SMPN 7 Mataram academic year 2018/2019. There were because the score of the experimental groups were higher than of the control groups, in which for the mean of deviation score in the experimental groups were 23.7142 and 168 then the control groups were 8.1428 and 2. On the other hand, because of the fact that this research used two tails so that the value of the t- (1990) and (1989) in degree of freedom (df) 80 and 82. they can be seen in table 2. 
Table 2 Result of t-test and t-table

\begin{tabular}{|l|l|l|l|}
\hline \multirow{2}{*}{ t-test } & \multicolumn{3}{|l|}{ t-table } \\
\cline { 2 - 4 } & Df & 0.05 & 0.01 \\
\hline 5.3839 & 80 & 1.990 & 2.6386 \\
\hline
\end{tabular}

\begin{tabular}{|l|l|l|l|}
\hline \multirow{2}{*}{ t-test } & t-table & \multicolumn{3}{|l|}{} \\
\cline { 2 - 4 } & Df & 0.05 & 0.01 \\
\hline 7.0249 & 82 & 1.989 & 2.6371 \\
\hline
\end{tabular}

Table 4.1.4 shows that there is significant effect of using learning environment through pictures and vocabulary lists strategy in the confidence level of .05 because the t-test results are higher than the ttable. The t-test results are 5.3839 and 7.0249 then t-tables are 1.990 and 1.989. Moreover, in the confidence level of .01 the -test results are also higher than then t-table. The results of t-test are 5.3839 and 7.0249 while the t-tables are 2.6386 and 2.6371. Therefore, based on the testing hypothesis criteria which was provided in chapter III that : if the t-test $<\mathrm{t}$ - is failed to be rejected. The significant effect showed either in the confidence level .05 or in the confidence level of .01 . in the other words, the null hypothesis (H0) which stated that there is no effect of learning environment through pictures and vocabulary lists toward vocabulary acquisition is rejected. Thus, it was indicated that the alternative hypothesis $(\mathrm{H})$ which stated that there is a significant effect of learning environment through pictures and vocabulary lists toward vocabulary acquisition is accepted. From the result which was found, it can be concluded that learning environment through pictures and vocabulary lists gave significant effect on students' vocabulary acquisition at grade VII of SMPN 7 Mataram. It was because the results of t-test were 5.3839 and 7.0249, its meant that the t-test in the degree of freedom (80) and (82) were higher than the confidence level of .05 (1990) and (1989) and .01 (2.6386) and (2.6371), in two tails.

On the other hand, learning environment through pictures and vocabulary lists gave positive effect on students' vocabulary acquisition. It could be seen from the different results of the pre-test and the post-test in the experimental classes. In addition, learning environment through pictures and vocabulary lists was also enjoyable. learning environment through pictures and vocabulary lists was easy to implement and created an easy way to understand visual representation of the causes, categories of causes, and the need. Moreover, by using learning environment through pictures and vocabulary lists strategy the students were able to focus on the group on the possible causes or factors that influenced the problem or need. Even after the need had been addressed, learning environment through pictures and vocabulary lists diagram showed many areas of weakness that can be revised. Base on the comment also, it was found that learning environment through pictures and vocabulary lists also help the students in memorizing the vocabulary easily and the vocabulary is settled in their mind. As the conclusion learning environment through pictures and vocabulary lists strategy gave an effect on vocabulary acquisition students at grade VII of SMPN 7 Mataram academic year 2018/2019. 


\section{References}

Allen, Virginia French. (1983). Technique in Teaching Speaking. New York: Oxford University Press. P.24.

Arikunto, Suharsimi. (2010). Prosedur Penelitian: Suatu Pendekatan Praktik.Yogyakarta: Rineka Cipta.

Baddeley, A. D. (2004) .The Psychology of Memory. In: Baddeley, A. D., Kopelman, M. D. \& Wilson, B. A. (eds.) The Essential Handbook of Memory Disorders for Clinicians. New York, UK: Department of Psychology, University of York.

Diane \& Freeman_larsen (2000) techniques and principles in language teaching Ellis, Rod. 1985. Understanding Second Language Acquisition. Oxford: Oxford University Press. p.29.

Ellis, Rod. (1997). Second Language Acquisition. Oxford: Oxford University Press. Gnainoska, Anna. 1998. Teaching Vocabulary in Colour. English Teaching Forum, Vol. 36 No. 3 July-September. Retrieved November 26, 2007.

Hatch, E., Brown, C. (1995). Vocabulary, semantics, and language education. Cambridge: Cambridge University Press.

Harmer, J. (2001). The Practice of English Language Teaching. England: Pearson Longman. Thrid edition completely revised and update.

Loschky \&Bley-vroman. (1993). methods for effective teaching. New York; Allyn and Bacon Nation I. S. P. (1978.a.b.1990). Teaching and Learning Vocabulary. : New York: Newbury House. 165.

Newton, J\& Nation, I.S.P.(1997).Vocabulary and teaching.In Second Language Vocabulary Acquisition J.Coady and T.Huckin (eds.)Cambridge University Press, Cambridge:238-254.

Schmidt \& Frota. (1986). Developig Basic-conversatioal Ability in a Second Language: A Case Study of an Adult Learner. In R. Day (Ed.). Talking to Learn: Coversation in a Second Language. Rowley, MA. Newbury House.

Sutarjo. (2011). "Pembelajaran Nilai Karakter Kontruktivisme dan VCT sebagai Inovasi Pendekatan Pembelajaran Afektif”"'. Jakarta: Rajawali Pers,2013.

Wilkins, David. (1972) Linguistics in Language Teaching. London: Edward Arnold. P.111.

\section{Copyrights}

Copyright for this article is retained by the author(s), with first publication rights granted to the journal. This is an open-access article distributed under the terms and conditions of the Creative Commons Attribution license (http://creativecommons.org/licenses/by/4.0/). 